\title{
STUDIES ON REMOVAL OF METAL CONTENT USING COAL BASED
}

\section{ADSORBENT THROUGH WASTEWATER.}

\author{
R. U. Khope
}

Shri Shivaji Science College, Nagpur, Maharastra.

Corresponding author Email : khopey_ru@yahoo.in

\begin{abstract}
:
This paper presents the observations of the study on cobalt removal from a waste water by adsorption onto granular activated carbon. Similar study has also been done in presence of other metal namely zinc for comparison. The removal of cobalt ions by adsorption using granular activated carbon (GAC) in combination with Anthranilic acid was studied at constant temperature $25 \pm 0.5{ }^{\circ} \mathrm{C}$ and $\mathrm{pH}$. The equilibrium sorption isotherms are analyzed by the Freundlich and the Langmuir isotherms .
\end{abstract}

Keywords:

Adsorption, Cobalt, GAC F-200 , GAC F-400,Anthranilic acid, Zinc

\section{Introduction:}

Metal ion contamination of drinking water and wastewater especially with heavy metal ions such as cobalt, is a serious and ongoing problem. As a result of this pollution water bodies become a major environmental problem of the modern world. According to WHO[1] organization, about $80 \%$ of all diseases in human beings are caused by water. Cobalt is beneficial for humans because it is a part of vitamin B12, which is essential for human health. However, too high concentrations of cobalt may damage human health. When plants grow on contaminated water they will accumulate very small particles of cobalt, especially in the parts of the plant we eat, such as fruits and seeds. Water effluent of ceramic industry contains very high amounts of cobalt may cause serious health effects on human being [2]. The threshold limit value for cobalt fume and dust exposure is $0.1 \mathrm{mg} / \mathrm{m} 3$ in the U.S [3]. Even though heavy metal ions can be removed by physicochemical methods such as chemical precipitation, membrane separation [4-5] and ion exchange but adsorption has been shown to be economical alternative for removing metals from water [6-8]. 
Adsorption is an important technique in separation and purification processes which is useful in water and waste water industry to removal of color, odor and organic pollutant [9-10]. Among many types of adsorbent materials, activated carbons which can be produced from almost any carbonaceous materials are the most widely used, because of their large adsorptive capacity and low cost [11]. Adsorption is not always a single process. Often a combination of interaction is responsible for the association between a particular chemical (sorbate) and solid (sorbent)[12-19] . In the present work cobalt was removed using granular activated carbon Filtrasorb-400 (F-400) and Filtrasorb-200 (F200) containing adsorbed organic ligand such as Anthranilic acid and the effect of $\mathrm{Zn} 2+$ (co-metal) on adsorption was also studied.

\section{Material and Method:}

Granular Activated Carbon namely F-200 and F-400 gifted by Calgon Corporation, Pittsburgh, USA were used as adsorbents. These carbons showed very good resistance to abrasion and stability in form when they were used for long periods of time in contact with aqueous solutions. The selected grades of carbons were first subjected to the size fractionation and only the particles of size ranging between 1400 micron to 1600 micron were recovered. The GAC was then washed several times with warmed distilled water carefully without leading to any attrition and water then decanted with care. After decanting much of water, the entire lot of the carbon sample was then transferred to a glass petridish. The carbon sample was dried in an oven at a temperature of $100-110^{\circ} \mathrm{C}$ for twelve hours and stored in $\mathrm{CaCl} 2$ desiccator until use. All chemicals used were of AR grade. A stock solution of cobalt ions was prepared by dissolving required quantity of cobalt sulphate (E. Merck) in distilled water with a drop of sulphuric acid to prevent hydrolysis. The standardized cobalt solution was utilized for establishing a Beer"s law plot of absorbance versus concentration of solutions. For this purpose $10 \mathrm{ml}$ of the standard solution was diluted to one liter and various compositions with distilled water of total 
volume $20 \mathrm{ml}$ were made. To these solutions $1 \mathrm{ml}$ of $1 \%$ sodium acetate trihydrate and $2 \mathrm{ml} 0.2 \%$ Nitroso-R-salt was added. The liquid was boiled for one minute and $2 \mathrm{ml} \mathrm{1:1} \mathrm{nitric} \mathrm{acid} \mathrm{was} \mathrm{added} \mathrm{to} \mathrm{stabilize} \mathrm{the} \mathrm{red} \mathrm{orange}$ complex [20]. The solution was cooled, diluted to $50 \mathrm{ml}$ and absorbance measured at $425 \mathrm{~nm}$ against a blank using Digital Systronic Spectrometer Model 166. A sample of Anthranilic acid was recrystallised by the routine method. The experimental melting point of 145 OC was compared with the literature value 144.5 OC[21]. All experiments were carried out in batches of five units at a time. For determining the adsorption isotherms of cobalt ion on the different grades of carbon containing adsorbed ligand such as Anthranilic acid ,0.5 gm of the GACs were taken in clean shaking bottles and $200 \mathrm{ml}$ of 0.001M Anthranilic acid solution was shaken for about five hours using Remi Stirrers (Type L- 157 M/s Remi Udyog, Mumbai, India) in constant temperature bath at around $500 \mathrm{rpm}$. The solution was then filtered off and the carbon was washed thoroughly with distilled water. The carbon particles were then transferred to a clean shaking bottle and then $200 \mathrm{ml}$ of cobalt solution at a $\mathrm{pH}$ $=5$ was added carefully. The $\mathrm{pH}$ of the adsorptive solutions was adjusted using nitric acid, sodium hydroxide and buffer solutions when required. The systems were then stirred for five hours completely with same speed maintaining the temperature at $25 \pm 0.5{ }^{\circ} \mathrm{C}$. The initial and final concentration of the cobalt ion was then determined spectrophotometrically.

\section{Result and Discussion:}

The correlation of experimental adsorption data with the adsorption models was undertaken to gain an understanding of adsorption behavior and the heterogeneity of the adsorbent surface. The mathematical interpretation of the adsorption isotherms is studied using the two common models, namely Freundlich and Langmuir. The adsorption isotherms for different grades of granular activated carbon are shown in Fig.1 and 2. The amount of cobalt on the GAC chemically modified by ligand Anthranilic acid was determined using 
the equation q_e $=\left(\mathrm{C} \_-\mathrm{O}-\mathrm{C} \_\mathrm{e}\right) \times \mathrm{V} / \mathrm{W}$ where, qe $=$ Concentration of cobalt ion on the ligand loaded GAC in $\mathrm{mg} /$ millimoles of ligand $\mathrm{Co}=$ Initial concentration of cobalt ion in solution in $\mathrm{mg} / \mathrm{L}$. Ce $=$ Final concentration of the cobalt ion in solution in $\mathrm{mg} / \mathrm{L} . \mathrm{V}=$ Volume of solution in liters $\mathrm{W}=$ Millimoles of the ligand actually present on 0.5 gm of GAC. It is observed from the result in Table-1 that cobalt adsorption follows the trend F-400>F-200. The mathematical expression for the Langmuir model in terms of cobalt ion concentration in solution $\mathrm{Ce}(\mathrm{mg} / \mathrm{L})$ in equilibrium with that on ligand loaded GAC qe $(\mathrm{mg} /$ millimoles $)$ is given by q_e $=\left(\mathrm{Q}^{\wedge} \mathrm{o}\right.$ bC_e $) /\left(1+\mathrm{bC} \_\mathrm{e}\right)$ It can be written in its liberalized form as follows $1 / \mathrm{q} \_\mathrm{e}=1 /\left(\mathrm{Q}^{\wedge} \mathrm{O} b\right) \times 1 / \mathrm{C} \_\mathrm{e}+1 / \mathrm{Q} \_0$ Where, $\mathrm{Q}^{\circ}$ is the Langmuir constant related to the adsorption capacity $\mathrm{b}$ is the other Langmuir parameter related to the energy of adsorption. The Freundlich model can take the following form. q_e $=$ K_(f $). C_{-} \mathrm{e}^{\wedge}(1 / \mathrm{n})$ The equation may be linearised as

Freundlich constants. Fig. 3 to 6 illustrate the plot of Langmuir and Frendlich isotherms for F-200 and F-400. The plots of 1 /qe versus $1 /$ Ce were found to be linear indicating the applicability of Langmuir model. The parameters $\mathrm{Q}^{\circ}$ and $\mathrm{b}$ are Langmuir constants relating to the sorption capacity and adsorption energy respectively. The intercept and slope of the linear plots of $1 /$ qe vs. $1 / \mathrm{Ce}$ and of logqe vs $\log \mathrm{Ce}$ under given set of experimental conditions provide values of,Q0, b kf, and $1 / \mathrm{n}$ respectively. The corresponding Freundlich and Langmuir constants obtained are listed in Table-2. The values of $\mathrm{kf}$ and Q0 for F-400Anthranilic acid -Co2+ system were greater than those for F-200-Antranilic acid-Co2+ system, indicating the superiority of the former for this sorption process. The presence of co-metal $(\mathrm{Zn})$ results in the lowering of the cobalt ion adsorption due to hindrance caused by the cometal ions while cobalt diffuses into the pores. The values of qe in presence of $\mathrm{Zn} 2+$ follows the trend F-400$\mathrm{Co} 2+>\mathrm{F}-400(\mathrm{Co} 2+-\mathrm{Zn} 2+)$ and F-200-Co2+ > F-200-(Co2+-Zn2+) 


\section{Conclusion:}

From the adsorption isotherms it is seen that as Ce increases qe increases but at high concentration qe tends to be constant which indicates the formation of a monolayer of cobalt ions on the surface of GAC. The ligand adsorbed granular activated carbon showed high adsorption capacity in the removal of cobalt ion from aqueous solution. In present work the GAC F-400 adsorbs cobalt to a greater extent as compared to F-200. In the presence of zinc the amount of cobalt adsorbed on GAC decreases Adsorption was found to be in good agreements with Langmuir isotherm which indicates monolayer adsorption. Application of the Freundlich and Langmuir isotherm models gave good representations of the experimental data for cobalt sorption by GAC .

\section{Acknowledgement:}

The author is thankful to the Director of Laxminarayan Institute of Technology Nagpur and Principal, Science College Congress Nagar, Nagpur for providing necessary laboratory facilities to carry out the experimental work.

\section{Reference:}

WHO (World Health Organization), 2nd Ed., Vol 1, P 188 (1993).

Dara S.S."A text Book of Environment Chemistry and Pollution Control" S.Chand and Co. Ltd. New delhi,2002,1,215

A. G. Mukharjee, „Envirnmental Pollution and Health Hazards : Causes and Control", S. Galgotia, New Delhi, 1986, 58.

Yen T. F., Prentice Hall PTR, Upper Saddle River, 1999.

Kang S. Y., Lee J. U., Moon S. H., Kim K. W., Chemosphere, 2000, 56, 141.

Skinner J. H., Bassin N. J., The environmental protection agency"s hazardous waste research and development program., J. APCA, 1988.

Mahvi A. H., Int. J. Environ. Sci. Tech., 2008, 5(2), 275. 
Malakootian M., Almasi A., Hossaini H., Int. J. Environ. Sci. Tech., 2009, 5(2), 217.

Abbasi W. A. and M. Streat, Sep. Sci. Technol., 1994, 29, 1217.

Kirk-Orthmer, Encyclopedia of chemical Technology, Wiley-Interscience, USA, 1997, 24, Fourth Ed.

Zhonghua H., M. P. Shrinivasan and N. Yaming, Carbon, 2001, 39: 877.

Fabra A. R. , Duffard R., Evangelista de Duffard, Bull. Environ. Contam Toxicol., 1997, 59, 645.

Celis R. Hermosin M. C., Cox L. and Cornejo J., Environ. Sci. Technol., 1999, 33,1200 .

Bekbolet M., Yenigun O. and Yucel I., Water Air Soil Pollut., 1999, 111, 75.

Mahramanlioglu M., Kizilcikli I., Bicer I. O. and Tuncay M., J. Environ. Sci. Health, 200, B 35: 187.

Susarla S., Bhaskar G. V. and Bhamidimarri, Environ. Technol., 1993, 14, 159.

Sotelo J. L., Ovejero G., Delgado A. and Martinez I., Water Res., 2001, 36, 599.

Belmouden M., Assabbane A. and Ichou Y. A., Ann. Chim. Sci. Materiaux, $2001,26,79$.

Benoit P., Barriuso E. and Calver R.. Chemosphere, 1998, 37.

Vogel A. I., Quantitative inorganic analysis, 4th Edition, Longman Group Ltd. England, 1978, 739.

Vishnoi N. K., „Advanced Practical Organic Chemistry", Vikas Publishing House Pvt. Ltd., 1979, Vol. 1, 194. 
Table-1 VALUES OF qe max (mg/mmol) FOR ADSORPTION OF COBALT ION FROM SOLUTION BY GAC CONTAINING ADSORBED LIGAND (ANTHRANILIC ACID)

\begin{tabular}{|c|c|c|}
\hline Sr. No. & System & qe max (mg/mmol) \\
\hline 1 & GAC F-200-Anthranilic Acid-Co & 0.9313 \\
\hline 2 & GAC F-400-Anthranilic Acid-Co & 1.5160 \\
\hline 3 & GAC F-200-Anthranilic Acid-Co $^{2+}-\mathrm{Zn}^{2+}$ & 0.8852 \\
\hline 4 & GAC F-400-Anthranilic Acid-Co & 0.8244 \\
\hline
\end{tabular}

Table-2 ISOTHERM CONSTANTS

\begin{tabular}{|c|c|c|c|c|c|}
\hline \multirow{2}{*}{$\begin{array}{l}\text { Sr. } \\
\text { No. }\end{array}$} & \multirow[t]{2}{*}{ System } & \multicolumn{2}{|c|}{ Langmuir Constant } & \multicolumn{2}{|c|}{ Freundlich Constant } \\
\hline & & Q० & $b$ & $\mathrm{Kf}$ & $1 / n$ \\
\hline 1 & $\begin{array}{l}\text { GAC F-200- } \\
\text { Anthranilic Acid-Co }\end{array}$ & 1.7667 & 0.2254 & 0.3572 & 0.5990 \\
\hline 2 & $\begin{array}{c}\text { GAC F-400- } \\
\text { Anthranilic Acid-Co }\end{array}$ & 1.8867 & 0.6567 & 0.7870 & 0.3480 \\
\hline 3 & $\begin{array}{c}\text { GAC F-200- } \\
\text { Anthranilic Acid-Co } \\
-\mathrm{Zn}^{2+}\end{array}$ & 1.7452 & 0.2208 & 0.3459 & 0.6060 \\
\hline 4 & $\begin{array}{c}\text { GAC F-400- } \\
\text { Anthranilic Acid-Co } \\
-\mathrm{Zn}^{2+}\end{array}$ & 1.1454 & 0.4298 & 0.3926 & 0.4330 \\
\hline
\end{tabular}



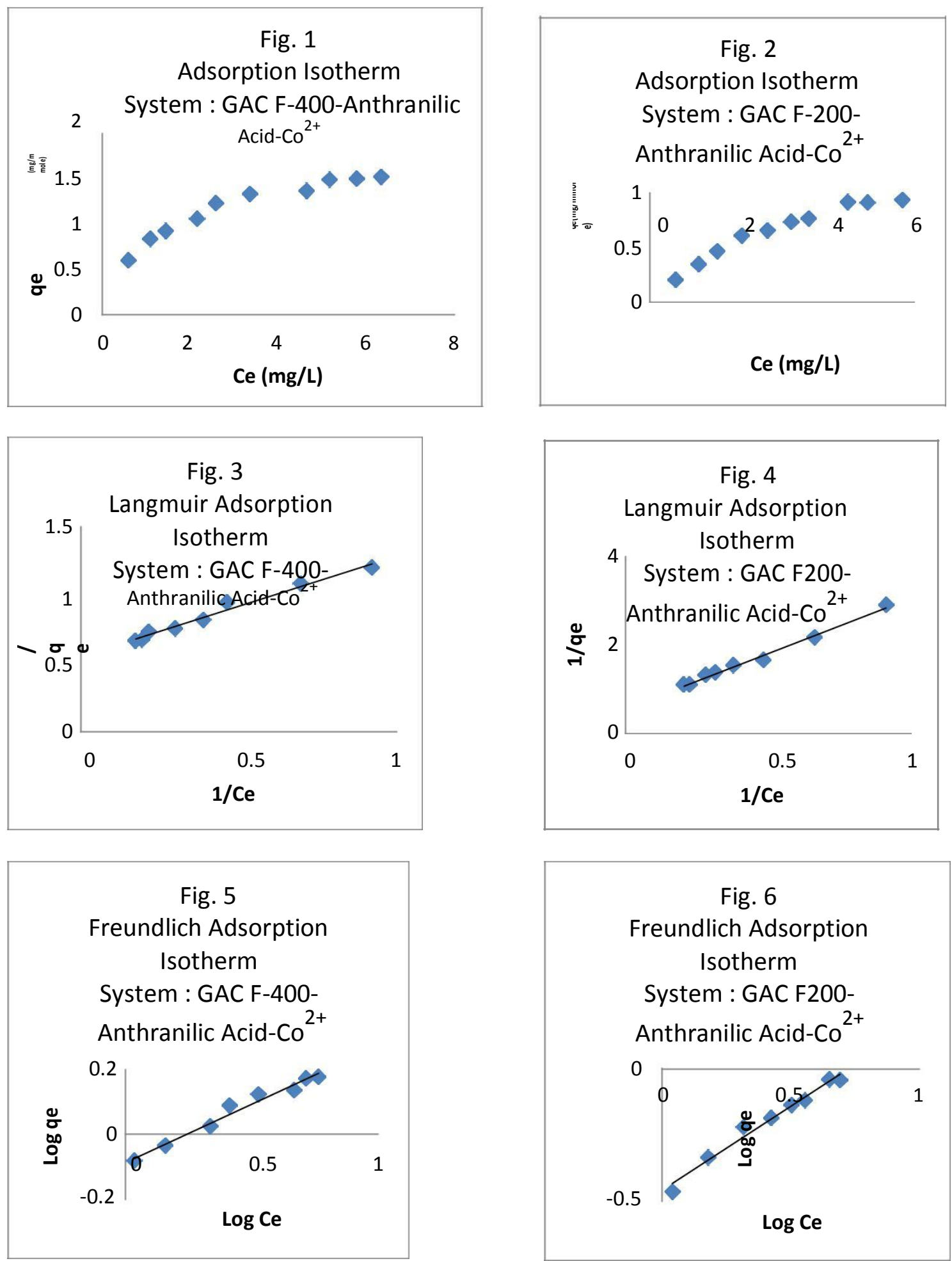
